\title{
On-the-Job Search with Match-Specific Amenities
}

\author{
James Albrecht \\ Georgetown University, CESifo, and IZA \\ Carlos Carrillo-Tudela \\ University of Essex, CEPR, CESifo, and IZA \\ Susan Vroman \\ Georgetown University, CESifo and IZA
}

October 14, 2017 


\begin{abstract}
We construct an equilibrium on-the-job search model in which workers value wages and amenities. We show by example that in a standard (Burdett/Mortensen) model with a distribution of worker tastes over amenities, worker mobility need not imply equilibrium wage dispersion.

Keywords: On-the-job search, amenities

JEL Codes: D38, J64, J31
\end{abstract}




\section{Introduction}

Models of on-the-job search offer an explanation for wage differentials across identical workers. With on-the-job search, firms can be indifferent between low and high wage offers. A firm that offers a low wage has difficulty attracting and retaining workers, but its profit per worker employed is relatively high. A firm that offers a high wage finds it easier to attract and retain workers, but its profit per worker employed is relatively low. On-the-job search thus introduces the "volume-margin tradeoff" that lies behind theories of equilibrium wage dispersion.

In most models of on-the-job search, e.g., Burdett and Mortensen (1998), a worker's decision to move from one firm to another is based solely on the wages offered by the two firms. However, non-wage characteristics likely also play an important role. (See Bonhomme and Jolivet, 2009, and Sullivan and To, 2014, for empirical evidence.) A worker may prefer firm A to firm B even though $\mathrm{B}$ offers a higher wage if he or she prefers the amenities associated with firm A to those associated with firm B.

In this note, we examine an equilibrium model of on-the-job search in which workers care both about wages and about job-specific amenities. We use a framework defined by two further assumptions. The first is that workers have heterogeneous preferences over non-wage characteristics, i.e., we assume "horizontal" rather than "vertical" differentiation across job amenities. Second, we assume that worker preferences over these amenities are private information. These assumptions imply that firms cannot use their wage offers to "price" the non-wage characteristics of their jobs. ${ }^{1}$

We focus on a particular question, namely, when workers care about both wages and amenities, does on-the-job search necessarily lead to equilibrium wage dispersion as in Burdett and Mortensen (1998)? The answer is "no." Using a uniform distribution, we show by example that if preferences over the amenity are sufficiently dispersed, there is an equilibrium in which all firms post the same wage.

\footnotetext{
${ }^{1}$ Other models of equilibrium search in which workers care both about wages and amenities include Hwang, Mortensen and Reed (1998) and Albrecht and Jovanovic (1986). In Hwang et al. (1998), workers all have the same known preferences over amenities. Amenities can thus be priced, so the model is one of compensating differentials as in Rosen (1986), and the equilibrium is essentially that of Burdett and Mortensen (1998) except that firms offer flow utilities rather than wages. Albrecht and Jovanovic (1986) make the same assumptions (horizontal differentiation, private information) that we do but without incorporating on-the-job search. That paper compares the equilibrium job acceptance decision of the unemployed in a random search model like ours to the corresponding decision in a competitive search benchmark.
} 


\section{$2 \quad$ Model}

We use the simplest version of Burdett and Mortensen (1998) as our starting point. Time is continuous, and only steady states are considered. There are unit masses of homogeneous workers and homogeneous firms, and all agents have a zero rate of time preference. Firms live forever. They receive revenue $p$ per worker employed per unit of time and maximize expected steady-state flow profit. Workers have finite lives, exiting the market at Poisson rate $\phi$. These exits are offset by the entry of new workers into unemployment. Job offers arrive at Poisson rate $\lambda$, the same whether employed or unemployed, and jobs end (workers move from employment to unemployment) at Poisson rate $\delta$. Workers maximize expected lifetime payoffs.

When a job offer arrives, the worker draws a match-specific flow payoff (amenity), $\varepsilon$, and the firm offers a wage $w$ on a take-it-or-leave-it basis. The amenity is a random draw from an exogenous continuous distribution function $\Gamma(\varepsilon)$ with corresponding density $\gamma(\varepsilon)$, which is symmetric around zero with support $[-\bar{\varepsilon}, \bar{\varepsilon}]$. The realization of this draw is the worker's private information. Wage offers are distributed across firms according to an endogenous distribution function $F(w)$ with support $[\underline{w}, \bar{w}]$. A worker who accepts a job offering wage $w$ and amenity $\varepsilon$ realizes a flow payoff of $z=w+\varepsilon$ for the duration of the match. Convolution then gives a continuous distribution of flow payoffs across job offers:

$$
H(z)=\int_{\underline{w}}^{\bar{w}} \Gamma(z-w) d F(w) .
$$

Unemployed workers receive flow payoff $b<p$. An unemployed worker thus accepts a job offer if and only if its flow payoff, $z$, is at least as great as $b$. An employed worker accepts a new job if and only if its flow payoff is strictly greater than the current job's flow payoff.

We begin by characterizing the relevant steady states. Using these steady state measures, we then derive firms' steady-state flow profits. Let $u$ denote the steady-state measure of unemployed workers. The inflow to unemploy-

ment during any time interval of length $d t$ equals the flow of workers from employment into unemployment plus the new entrants who replace workers who exit the market from employment, i.e., $(\delta+\phi) d t(1-u)$. The corresponding outflow is $\lambda d t(1-H(b)) u$, so in steady state,

$$
u=\frac{\phi+\delta}{\phi+\delta+\lambda(1-H(b))} .
$$


Next, let $G(z)$ denote the proportion of employed workers receiving flow payoff of $z$ or less. Note that $G(z)=0$ for $z<b$. Hence, for $z \geq b$, the inflow of unemployed workers to employment with a payoff $z$ or less is $\lambda d t[H(z)-H(b)] u$. The outflow is given by those workers who exit the market or were displaced from employment or who received an offer with a payoff greater than $z$, i.e., $[\phi+\delta+\lambda(1-H(z))] d t G(z)(1-u)$, so in steady state,

$$
G(z)=\left[\frac{\lambda[H(z)-H(b)]}{\phi+\delta+\lambda(1-H(z))}\right] \frac{u}{1-u} .
$$

Now consider a firm offering a wage $w$ such that $w+\bar{\varepsilon} \geq b$, and let $L(z \mid w)$ denote the steady state number of workers receiving flow payoff $z$ in this firm. The flow of such workers into the firm in any time interval of length $d t$ consists of the unemployed workers who contacted the firm and drew a match-specific payoff $\varepsilon=z-w \geq b$ plus the employed workers with flow payoff less than $z$ who contacted the firm and drew the same $\varepsilon=z-w$. The hiring inflow is thus $\lambda d t[u+(1-u) G(z)] \gamma(z-w)$ while the corresponding outflow is $[\phi+\delta+\lambda(1-H(z))] d t L(z \mid w)$. Substituting (2) and (3) into the hiring rate and equating inflows to outflows gives

$$
L(z \mid w)=\frac{\lambda(\phi+\delta) \gamma(z-w)}{[\phi+\delta+\lambda(1-H(z))]^{2}} .
$$

This describes the steady state number of workers with flow payoff $z$ employed at a firm offering $w \geq b-\bar{\varepsilon}$.

A firm offering wage $w$ thus has an expected labor force of

$$
L(w)=\int_{\max [b, w-\bar{\varepsilon}]}^{w+\bar{\varepsilon}} \frac{\lambda(\phi+\delta) \gamma(z-w)}{[\phi+\delta+\lambda(1-H(z))]^{2}} d z
$$

and an expected steady-state profit of

$$
\Omega(w)=(p-w) L(w) .
$$

The lower limit in the integral defining $L(w)$ reflects the facts that (i) no worker will accept a job offering $z<b$ and (ii) the lowest flow payoff at a firm offering $w$ is $w-\bar{\varepsilon}$. Each firm chooses its wage to maximize $\Omega(w)$ given the distribution of wages posted by other firms and the optimal search strategy of workers. Let $\bar{\Omega}=\max _{w} \Omega(w)$.

\subsection{Equilibrium}

Definition: An equilibrium is a quadruple $\{u, F, G, H\}$ such that 
(i) workers search optimally given $H$;

(ii) $u, G$ and $H$ are consistent with steady state given wage offers $F$ and optimal worker search;

(iii) firms choose wages to maximize $\Omega(w)$ given the all other firms' wage offers and the optimal search strategy of workers.; i.e.,

$$
\begin{array}{ll}
\Omega(w)=\bar{\Omega} & \text { for all } w \text { where } d F(w)>0 ; \\
\Omega(w) \leq \bar{\Omega} & \text { for all } w \text { where } d F(w)=0 .
\end{array}
$$

As $p>b$, each firm can offer a wage that attracts some workers and makes positive expected profit. That is, in equilibrium $\bar{\Omega}>0$.

Burdett and Mortensen (1998) show that when $\Gamma$ is degenerate, the equilibrium wage offer distribution cannot have mass points. If there were a mass point, say at $\tilde{w}<p$, a firm offering $\tilde{w}$ would strictly increase its expected profit by offering $\tilde{w}+\eta$, where $\eta>0$ is arbitrarily small. This deviation would increase the hiring rate of the firm discontinuously, while the profit per hire would decrease continuously. However, when workers' job acceptance decisions also depend on a continuously distributed matchspecific component, as considered here, the hiring rate no longer need be discontinuous at a mass point. Hence, one cannot a priori rule out the possibility of mass points in $F$.

In the next section we analyze the conditions under which a single-masspoint equilibrium exists. In such an equilibrium, all firms offer the same wage and workers change jobs purely due to their preferences over amenities. To illustrate this we restrict our analysis to the case in which $\Gamma$ is uniform on $[-\bar{\varepsilon}, \bar{\varepsilon}]$.

\section{Single-wage equilibrium}

Consider a candidate equilibrium in which all firms offer a wage $w_{0}$. Let $L\left(w ; w_{0}\right)$ be the expected workforce of a potential deviant offering wage $w$, and let $\Omega\left(w ; w_{0}\right)$ be the corresponding expected profit flow. Since $F$ is degenerate at $w_{0}$, we have $H(z)=\Gamma\left(z-w_{0}\right)$. Thus

$\Omega\left(w ; w_{0}\right)=(p-w) L\left(w ; w_{0}\right)=(p-w) \int_{\max [b, w-\bar{\varepsilon}]}^{w+\bar{\varepsilon}} \frac{\lambda(\phi+\delta) \gamma(z-w)}{\left[\phi+\delta+\lambda\left(1-\Gamma\left(z-w_{0}\right)\right)\right]^{2}} d z$.

In a single-wage equilibrium, there is a unique $w_{0}$ such that $w_{0}=\arg \max \Omega\left(w ; w_{0}\right)$. A sufficient condition for the existence of a unique single-wage equilibrium is therefore the existence of a unique $w_{0}$ such that $\Omega^{\prime}\left(w_{0} ; w_{0}\right)=0$ and $\Omega^{\prime \prime}\left(w_{0} ; w_{0}\right)<0$. 
Whether such an equilibrium exists depends, of course, on the distribution of the match-specific amenity. If, in particular, the distribution of $\varepsilon$ is degenerate at zero (the case considered in Burdett and Mortensen 1998), then a single-wage equilibrium does not exist. For other amenity distributions, however, a single-wage equilibrium does exist. We illustrate this by considering the case in which $\varepsilon$ is uniform on $[-\bar{\varepsilon}, \bar{\varepsilon}]$. In this case, we show that if the amenity distribution is sufficiently dispersed, i.e., if $\bar{\varepsilon}$ is sufficiently large, then an equilibrium exists in which all firms post the same wage. Specifically, we show

Proposition 1 Let $\varepsilon$ be uniform on $[-\bar{\varepsilon}, \bar{\varepsilon}]$ with $\bar{\varepsilon} \geq(p-b)\left(\frac{\phi+\delta+\lambda}{3(\phi+\delta)+\lambda}\right)$. Then there exists a unique single-wage equilibrium.

To verify this, we proceed as follows. Let $w_{0}$ be the candidate equilibrium wage, and let $\underline{z}_{0}=w_{0}-\bar{\varepsilon}$ and $\bar{z}_{0}=w_{0}+\bar{\varepsilon}$ be the lowest and highest flow payoffs workers can achieve in the candidate equilibrium. Since $\varepsilon$ is uniform on $[-\bar{\varepsilon}, \bar{\varepsilon}]$, we have $\gamma(z-w)=1 / 2 \bar{\varepsilon}$ and $\Gamma\left(z-w_{0}\right)=\left(z-w_{0}+\bar{\varepsilon}\right) / 2 \bar{\varepsilon}$. Assuming that $\underline{z}_{0} \leq b$ (an assumption that we will show follows from the restriction placed above on $\bar{\varepsilon}$ ), the expected steady-state profit for a firm posting wage $w$ when all other firms post $w_{0}$ is

$$
\Omega\left(w ; w_{0}\right)=(p-w) \int_{b}^{w+\bar{\varepsilon}} \frac{2 \bar{\varepsilon} \lambda(\phi+\delta)}{\left[2 \bar{\varepsilon}(\phi+\delta)+\lambda\left(w_{0}+\bar{\varepsilon}-z\right)\right]^{2}} d z .
$$

Note that $\Omega\left(w ; w_{0}\right)=0$ for $w+\bar{\varepsilon} \leq b$ (since no workers will accept a wage below $b)$ and that $\Omega\left(w ; w_{0}\right) \leq 0$ for $w \geq p$. That is, the firm's optimal wage must lie in $[b-\bar{\varepsilon}, p]$.

Using a change of variable and integrating,

$$
\Omega\left(w ; w_{0}\right)=\frac{(p-w) 2 \bar{\varepsilon}(\phi+\delta) \lambda(w+\bar{\varepsilon}-b)}{\left[2 \bar{\varepsilon}(\phi+\delta)+\lambda\left(w_{0}-w\right)\right]\left[2 \bar{\varepsilon}(\phi+\delta)+\lambda\left(w_{0}+\bar{\varepsilon}-b\right)\right]} .
$$

Differentiating with respect to $w$ and letting $a=2 \bar{\varepsilon}(\phi+\delta)$ then gives

$\Omega^{\prime}\left(w ; w_{0}\right)=\frac{a \lambda}{a+\lambda\left(w_{0}+\bar{\varepsilon}-b\right)}\left(\frac{\left[a+\lambda\left(w_{0}-w\right)\right][b-\bar{\varepsilon}-w]+(p-w)\left(a+\lambda\left(w_{0}-b+\bar{\varepsilon}\right)\right)}{\left[a+\lambda\left(w_{0}-w\right)\right]^{2}}\right)$.

Any critical value $w^{*}$ must therefore solve the quadratic equation

$$
\left[a+\lambda\left(w_{0}-w^{*}\right)\right]\left[b-\bar{\varepsilon}-w^{*}\right]+\left(p-w^{*}\right)\left(a+\lambda\left(w_{0}-b+\bar{\varepsilon}\right)\right)=0 .
$$


In any candidate equilibrium $w_{0} \geq b-\bar{\varepsilon}$, so evaluating $\Omega^{\prime}\left(w ; w_{0}\right)$ at $w=b-\bar{\varepsilon}$ yields

$$
\Omega^{\prime}\left(b-\bar{\varepsilon} ; w_{0}\right)=\frac{a \lambda(p-(b-\bar{\varepsilon}))}{\left[a+\lambda\left(w_{0}-(b-\bar{\varepsilon})\right)\right]^{2}}>0 .
$$

Since (i) $\Omega^{\prime}\left(b-\bar{\varepsilon} ; w_{0}\right)>0$, (ii) $\Omega\left(b-\bar{\varepsilon} ; w_{0}\right)=\Omega\left(p ; w_{0}\right)=0$, and (iii) (8) is a quadratic equation, it follows that there is a unique $w^{*} \in(b-\bar{\varepsilon}, p)$ that solves equation (8) and that this critical value maximizes rather than minimizes the firm's expected profit.

The final step is to find a $w_{0}$ that is its own best response. To do so we solve equation (8) letting $w^{*}=w_{0}$. The equilibrium $w_{0}$ then solves

$$
\left(p-w_{0}\right)=\frac{a\left(w_{0}+\bar{\varepsilon}-b\right)}{\left[a+\lambda\left(w_{0}+\bar{\varepsilon}-b\right)\right]} .
$$

To show that a unique solution exists, note that the LHS of equation (9), $\Psi_{1}\left(w_{0}\right)=\left(p-w_{0}\right)$, is a strictly decreasing linear function of $w_{0}$ that goes from $\Psi_{1}(b-\bar{\varepsilon})=p-b+\bar{\varepsilon}$ to $\Psi_{1}(p)=0$ while the RHS, $\Psi_{2}\left(w_{0}\right)=$ $\frac{a\left(w_{0}+\bar{\varepsilon}-b\right)}{\left[a+\lambda\left(w_{0}+\bar{\varepsilon}-b\right)\right]}$, is a strictly increasing and concave function that goes from $\Psi_{2}(b-\bar{\varepsilon})=0$ to $\Psi_{2}(p)=\frac{a(p+\bar{\varepsilon}-b)}{[a+\lambda(p+\bar{\varepsilon}-b)]}>0$. Continuity of $\Psi_{1}$ and $\Psi_{2}$ implies a unique intersection. That is, there exists a unique $w_{0}$ that solves equation (9). The wage $w_{0}$ maximizes each firm's steady-state expected profit given that all other firms post $w_{0}$.

Finally, we provisionally assumed that $\underline{z}_{0} \leq b$. Equation (9) gives a parametric restriction on $\bar{\varepsilon}$ such that this inequality holds, namely, $\bar{\varepsilon} \geq$ $(p-b)\left(\frac{\phi+\delta+\lambda}{3(\phi+\delta)+\lambda}\right)$. To see this, suppose $\underline{z}_{0}=w_{0}-\bar{\varepsilon}=b$. In this case, the equilibrium wage not only satisfies equation (9) but also satisfies the restriction $w_{0}=b+\bar{\varepsilon}$. Substituting the latter expression into equation (9) and solving for $\bar{\varepsilon}$ yields

$$
\bar{\varepsilon}=(p-b)\left(\frac{\phi+\delta+\lambda}{3(\phi+\delta)+\lambda}\right) .
$$

From equation (9), $w_{0}$ is decreasing in $\bar{\varepsilon}$. Thus, as $\bar{\varepsilon}$ increases, $\underline{z}_{0}=w_{0}-\bar{\varepsilon}$ decreases, and the assumption that $\underline{z}_{0} \leq b$ remains valid.

\section{Conclusion}

In this note, we have constructed an equilibrium on-the-job search model in which workers care about both wages and amenities. We have shown by 
example that in a standard on-the-job search model, worker mobility need not imply equilibrium wage dispersion.

\section{References}

[1] Albrecht, James and Boyan Jovanovic (1986), The Efficiency of Search under Competition and Monopsony, Journal of Political Economy, 94(6), 1246-57.

[2] Bonhomme, Stéphane and Grégory Jolivet (2009), The Pervasive Absence of Compensating Differentials, Journal of Applied Econometrics, 24(5), 763-95.

[3] Burdett, Kenneth and Dale Mortensen (1998), Wage Differentials, Employer Size and Unemployment, International Economic Review, 39(2), $25 \%-73$.

[4] Hwang, Hae-shin, Dale Mortensen and W. Robert Reed (1998), Hedonic Wages and Labor Market Search, Journal of Labor Economics, 16(4), $815-47$.

[5] Rosen, Sherwin (1986), The Theory of Equalizing Differences, in Orley Ashenfelter and Richard Layard, editors, Handbook of Labor Economics, vol. 1. Amsterdam:Elsevier, 641-92.

[6] Sullivan, Paul and Ted To (2014), Search and Nonwage Job Characteristics, Journal of Human Resources, 24(2), 472-50\%. 